\author{
А.В. Аксёнов ${ }^{1}$, Е.А. Ивановская ${ }^{2}$ \\ ${ }^{1}$ ФГБоУ ВО «Южно-Уральский государственный медицинский университет» Министерства здравоохранения Российской \\ Федерации; Россия, г. Челябинск \\ ${ }^{2}$ МАУЗ «Детская городская клиническая больница № 8»; Россия, г. Челябинск
}

\title{
PЕЗЮМЕ
}

\begin{abstract}
Цель статьи: демонстрация клинических случаев успешного применения адалимумаба у детей с ювенильным идиопатическим артритом (ЮИА), ассоциированным с увеитом.

Основные положения. Одним из экстраартикулярных проявлений ЮИА является увеит - воспаление сосудистого тракта глаза. Увеит, ассоциированный с ЮИА, возникает в основном у маленьких девочек с олигоартритом, ранним дебютом серонегативного полиартрита; у пациентов с артритом, ассоциированным с энтезитом и псориатическим артритом. В статье представлены клинические случаи применения адалимумаба у детей с ЮИА и увеитом при неэффективности лечения метотрексатом и местными глюкокортикостероидами.

Заключение. ЮИА, ассоциированный с увеитом, представляет собой одну из наиболее инвалидизирующих категорий ЮИА, поскольку нередко, даже при своевременном и правильно назначенном лечении, приводит к серьезным осложнениям со стороны глаз: катаракте, глаукоме, а иногда и слепоте. На сегодняшний день имеется препарат адалимумаб, представляющий собой человеческие моноклональные антитела к фактору некроза опухоли $\alpha$, позволяющий добиться ремиссии увеита при неэффективности применения метотрексата и местных глюкокортикостероидов, а также отсрочить появление осложнений со стороны глаз.

Ключевые слова: ювенильный идиопатический артрит, увеит, адалимумаб, дети.
\end{abstract}

Вклад авторов: Аксёнов А.В. - обзор публикаций по теме статьи, написание текста рукописи, утверждение статьи в печать; Ивановская Е.А. наблюдение, сбор материала и проведение лечебных мероприятий.

Конфликт интересов: авторы заявляют об отсутствии возможных конфликтов интересов.

Для цитирования: Аксёнов А.В., Ивановская Е.А. Опыт успешного применения адалимумаба у детей с ювенильным идиопатическим артритом, ассоциированным с увеитом. Доктор.Ру. 2021; 20(10): 73-75. DOI: 10.31550/1727-2378-2021-20-10-73-75

\section{Successful Use of Adalimumab in Children with Uveitis-Associated Juvenile Idiopathic Arthritis}

\author{
A.V. Aksenov ${ }^{1}$, E.A. Ivanovskaya ${ }^{2}$ \\ ${ }_{1}^{1}$ South Ural State Medical University of the Ministry of Health of the Russian Federation; 64 Vorovskiy Str., Chelyabinsk, Russian \\ Federation 454092 \\ ${ }^{2}$ Children's City Clinical Hospital No.8; 2 Druzhby Str., Chelyabinsk, Russian Federation 454047
}

\section{ABSTRACT}

Objective of the Paper: To describe clinical cases of successful use of adalimumab in children with uveitis-associated juvenile idiopathic arthritis (JIA).

Key Points. One of the extraarticular manifestations of JIA is uveitis, i. e. inflammation of the vascular tract of the eye. JIA-associated uveitis is diagnosed primarily in small girls with oligoarthritis, early seronegative polyarthritis; in patients with arthritis associated with enthesitis and psoriatic arthritis. The article describes clinical cases of the use of adalimumab in JIA and uveitis where the therapy with methotrexate and topical glucocorticosteroids fails.

Conclusion. Uveitis-associated JIA is one of the most disabling forms of JIA, since, despite timely and adequate management, very often it results in severe ocular complications: cataract, glaucoma and even blindness. Adalimumab, a human anti-TNF $\alpha$ monoclonal antibody, is available and it helps in achieving uveitis remission where methotrexate and topical glucocorticosteroids fail, as well as in delaying ocular complications.

Keywords: juvenile idiopathic arthritis, uveitis, adalimumab, children.

Contributions: Aksenov, A.V. - thematic publications reviewing, text of the article, approval of the manuscript for publication; Ivanovskaya, E.A. examination, material collection and therapeutic interventions.

Conflict of interest: The authors declare that they do not have any conflict of interests.

For citation: Aksenov A.V., Ivanovskaya E.A. Successful Use of Adalimumab in Children with Uveitis-Associated Juvenile Idiopathic Arthritis. Doctor.Ru. 2021; 20(10): 73-75. (in Russian). DOI: 10.31550/1727-2378-2021-20-10-73-75

Аксёнов Александр Владимирович (автор для переписки) - к. м. н., доцент кафедры пропедевтики детских болезней и педиатрии ФГБоУ ВО ЮугмУ Минздрава России. 454092, Россия, г. Челябинск, ул. Воровского, д. 64. eLIBRARY.RU SPIN: 8688-8874. E-mail: alexandr.axyonov@yandex.ru Ивановская Елена Алексеевна - заведующая ревматологическим отделением МАУЗ «ДГКБ № 8». 454047, Россия, г. Челябинск, ул. Дружбы, d. 2. E-mail: Ivanovskaya.Elena@yandex.ru 


\section{ВВЕДЕНИЕ}

Ювенильный идиопатический артрит (ЮИА) - артрит неустановленной причины длительностью более 6 недель, развивающийся у детей в возрасте не старше 16 лет при исключении другой патологии суставов [1].

Одним из экстраартикулярных проявлений ЮИА является увеит - воспаление сосудистого тракта глаза. В большинстве случаев при ЮИА наблюдается передний увеит — иридоциклит, он имеет, как правило, подострое или хроническое течение.

По данным литературы, увеит может дебютировать за несколько лет до появления суставного синдрома [1]. Он возникает в основном у маленьких девочек с олигоартритом, ранним дебютом серонегативного полиартрита; у пациентов с артритом, ассоциированным с энтезитом и псориатическим артритом.

К основным клиническим проявлениям увеита относятся признаки раздражения глаз (слезотечение, ощущение «песка в глазах», покраснение конъюнктивы глаз), снижение остроты зрения, однако часто он протекает бессимптомно, что требует регулярного наблюдения у офтальмолога.

Нередко увеит при ЮИА осложняется лентовидной дегенерацией роговицы, катарактой, глаукомой и даже слепотой [1].

Лечение увеита, ассоциированного с ЮИА, включает в себя назначение местной терапии - противовоспалительных препаратов (в т. ч. дексаметазона), а при ее неэффективности и при тяжелом панувеите рекомендуются парабульбарные инъекции бетаметазона. Для профилактики и лечения иридохрусталиковых синехий рекомендуются м-холинолитические препараты в виде капель в глаза. Безусловно, местное лечение увеита необходимо сочетать с цитостатической терапией: в большинстве случаев применяется метотрексат, гораздо реже - циклоспорин.

Как известно, на сегодняшний день для лечения ЮИА достаточно широко стали использоваться генно-инженерные биологические препараты [2-9]. Согласно клиническим рекомендациям Союза педиатров России «Юношеский артрит» (2017), при лечении увеита, ассоциированного с ЮИА, при неэффективности метотрексата (отсутствии ремиссии увеита через 3 месяца) предлагается назначать адалимумаб, представляющий собой человеческие моноклональные антитела к ФН0- $\alpha$, подкожно в дозе 40 мг 1 раз в 2 недели детям с 13 до 17 лет и в дозе 24 мг/м² поверхности тела детям с 4 до 12 лет.

\section{КЛИНИЧЕСКОЕ НАБЛЮДЕНИЕ № 1}

Нами наблюдалась пациентка А., 15 лет, с диагнозом: Ювенильный паущиартрит с поражением глаз: Вялотекущий увеит обоих глаз. Афакия, лентовидная дегенерация роговицы, вторичная глаукома 3-4 А (оперированная) правого глаза. Вторичная 4В (медикаментозная) глаукома, бомбаж радужки, осложненная катаракта, лентовидная дегенерация роговицы левого глаза. Серонегативный пауциартрит по РФ. Рентгенологическая стадия О. Функциональный класс 2. Неактивная фаза.

Анамнез жизни. Ребенок от 1-й беременности, 1-х своевременных родов. Масса при рождении - 3950 г, рост - 51 см. Выписана из родильного дома на 3-и сутки. Психомоторное развитие на первом году жизни по возрасту. Учится хорошо. Месячные регулярные. Профилактические прививки до установления диагноза по возрасту. Наследственность по ревматической патологии не отягощена.

Из анамнеза заболевания. Девочка больна с 3 лет, когда при прохождении медицинской комиссии при поступлении в детский сад обнаружилось снижение остроты зрения. Тогда же впервые пациентку обследовали в офтальмологическом отделении, был выявлен увеит (передний иридоциклит).

Для исключения ревматологической природы увеита девочку направили на обследование в ревматологическое отделение МАУЗ «Детская городская клиническая больница № 8»г. Челябинска. С учетом наличия проявлений артрита правого коленного сустава (отека сустава, местной гипертермии над ним), патогномоничных проявлений ревматоидного увеита (наличия мелких преципитатов, лентовидной дегенерации роговицы обоих глаз) ревматолог выставил диагноз: Ювенильный пауциартрит, ассоциированный с увеитом.

Пациентке тогда же была назначена базисная терапия циклоспорином. На фоне приема данного препарата достигнута ремиссия по суставному синдрому, однако ремиссии по увеиту достигнуть не представилось возможным, поэтому в 2009 году циклоспорин был заменен на метотрексат. К сожалению, смена базисной терапии значительно на глазную симптоматику не повлияла: периодически возникали обострения увеита, требовавшие вновь повышения дозы местных гормональных препаратов, в 2015 году была диагностирована двусторонняя катаракта, а спустя полгода двусторонняя глаукома.

В 2018 году из-за отсутствия эффекта от метотрексата и появления возможности использования генно-инженерных препаратов было принято решение о назначении ребенку адалимумаба. Препарат назначили подкожно в дозе 24 мг/м² поверхности тела 1 раз в 2 недели.

Первая инъекция сделана 16.11.2018 г. После 3 инъекций данного препарата лечение самостоятельно было отменено в связи с учащением ОР3.

При плановом осмотре окулист 15.08.2019 г. зарегистрировал обострение увеита, вследствие чего были даны рекомендации по продолжению генно-инженерной биологической терапии. Лечение адалимумабом возобновлено 21.10.2019 г. в дозе 40 мг 1 раз в 2 недели подкожно.

В сентябре 2020 года девочке проведена лазерная иридэктомия на левом глазу. В настоящее время она продолжает получать подкожно адалимумаб в дозе 40 мг 1 раз в 2 недели, а также метотрексат в дозе 15 мг/м² поверхности тела подкожно.

На фоне применения адалимумаба наблюдается ремиссия увеита. Обострения суставного синдрома не отмечаются до настоящего времени.

Объективный статус: при физикальном осмотре отклонений от нормы нет, суставы интактны, их функция не нарушена.

\section{КЛИНИЧЕСКОЕ НАБЛЮДЕНИЕ № 2}

Нами наблюдалась пациентка Д., 12 лет, с диагнозом: Ювенильный пауциартрит с поражением глаз (увеит, лентовидная дегенерация роговицы обоих глаз). (еронегативный по РФ. Рентгенологическая стадия 2. Функциональный класс 1. Неактивная фаза.

Анамнез жизни. Ребенок от 1-й беременности, протекавшей на фоне уреаплазмоза, хронической фетоплацентарной недостаточности, хронической внутриутробной гипоксии плода; 1-х своевременных самостоятельных родов. Масса при рождении - 2450 г, рост - 48 см. Выписана из роддома домой на 10-е сутки жизни. До года росла и развивалась по возрасту. Естественное вскармливание до 8 месяцев. Состоит на диспансерном учете у оториноларинголога по поводу хронического тонзиллита. Привита по возрасту до 3 лет, затем медицинский отвод по поводу основного заболевания. Наследственность по ревматической патологии не отягощена. 
Из анамнеза заболевания. Девочка больна с апреля 2013 года, когда появилась клиника артрита правых коленного и голеностопного суставов, тогда же при обследовании в ревматологическом отделении МАУЗ «Детская городская клиническая больница № 8»г. Челябинска был выставлен диагноз ювенильного пауциартрита, назначен метотрексат в/м в дозе 10 мг в неделю, который был отменен в 2015 году в связи с длительной неактивной фазой заболевания.

В октябре 2017 года возникло обострение суставного синдрома, вследствие чего возобновлена терапия метотрексатом, однако его доза была повышена до 15 мг в неделю. В августе 2018 года на плановом осмотре у офтальмолога выявлен увеит обоих глаз: назначена гормональная терапия в виде капель в глаза.

Эффект от местной гормональной терапии отмечался кратковременный: при снижении дозы противовоспалительных препаратов в виде капель в глаза (с 6 до 3 капель в день) проявления увеита возобновлялись.

В начале 2020 года девочка перенесла пневмонию, после которой зафиксировано повышение активности в крови АСТ и АЛТ. В результате принято решение о замене метотрексата на лефлуномид.

Вначале пациентка получала лефлуномид в дозе 10 мг внутрь ежедневно, затем его доза была повышена до 15 мг. Данную дозу препарата девочка получает по сегодняшний день.

На очередном осмотре окулиста 3 декабря 2020 года зарегистрировано обострение увеита. В связи с этим паци-

\section{ЛИТЕРАTУPA / REFERENCES}

1. Алексеева Е.И., Литвицкий П.Ф.; Баранов А.А., ред. Ювенильный ревматоидный артрит: этиология, патогенез, клиника, алгоритмы диагностики и лечения. Руководство для врачей, преподавателей, научных сотрудников. М.: Веди; 2007. 368 с. [Alekseeva E.I., Litvitskiy P.F.; Baranov A.A., ed. Juvenile rheumatoid arthritis: aetiology, pathogenesis, clinical findings, algorithms of diagnosis and management. Manual for medical professional, teachers, and scientists. M.: Vedi; 2007. 368 p. (in Russian)]

2. Серая В.А., Жолобова Е.С., Витебская А.В. и др. Динамика роста детей с системной формой ювенильного идиопатического артрита на фоне терапии тоцилизумабом и другими генно-инженерными биологическими препаратами. Вопросы практической педиатрии. 2016; 11(2): 15-22. [Seraya V.A., Zholobova E.S., Vitebskaya A.V. et al. Dynamics of growth of children with systemic form of juvenile idiopathic arthritis during therapy with tocilizumab and other biological agents. Clinical Practice in Pediatrics. 2016; 11(2): 15-22. (in Russian)]. DOI: 10.20953/1817-7646-2016-2-15-22

3. Horneff G., Schulz A.C., Klotsche J. et al. Experience with etanercept, tocilizumab and interleukin-1 inhibitors in systemic onset juvenile rheumatoid arthritis patients from the BIKER registry. Arthritis Res. Ther. 2017; 19(1): 256. DOI: 10.1186/s13075-017-1462-2

4. Kikuchi J., Kondo T., Shibata A. et al. Efficacy and tolerability of six-week extended dosing interval with tocilizumab therapy in a prospective cohort as remission maintenance in patients with rheumatoid arthritis. Mod. Rheumatol. 2018; 28(3): 444-51. DOI: 10.1080/14397595.2017.1366092

5. Pardeo M., De Benedetti F., Wang J. et al. Neutropenia during tocilizumab treatment is not associated with infection risk in ентка была госпитализирована в ревматологическое отделение МАУЗ «Детская городская клиническая больница № 8» г. Челябинска для решения вопроса о назначении генно-инженерной биологической терапии.

С учетом частых обострений увеита на фоне базисной иммуносупрессивной терапии в начале декабря 2020 года девочке назначен адалимумаб подкожно в дозе 24 мг/м² поверхности тела 1 раз в 2 недели. Уже в январе 2020 года офтальмолог отметил уменьшение проявлений иридоциклита, а с февраля по сегодняшний день - неактивная фаза увеита. Последнее введение адалимумаба произведено в мае текущего года.

Объективный статус: при физикальном осмотре отклонений от нормы нет, суставы интактны, их функция не нарушена.

\section{ЗАКЛЮЧЕНИЕ}

Ювенильный идиопатический артрит (ЮИА), ассоциированный с увеитом, представляет собой одну из наиболее инвалидизирующих разновидностей ЮИА, поскольку нередко, даже при своевременном и правильно назначенном лечении, приводит к серьезным осложнениям со стороны глаз: катаракте, глаукоме, а иногда и слепоте. На сегодняшний день имеется препарат адалимумаб, представляющий собой человеческие моноклональные антитела к ФН0- $\alpha$, позволяющий добиться ремиссии увеита при неэффективности применения метотрексата и местных глюкокортикостероидов, а также отсрочить появление осложнений со стороны глаз.

systemic or polyarticular-course juvenile idiopathic arthritis. J. Rheumatol. 2019; 46(6): 1117-26. DOI: 10.3899/jtheum.180795

6. Аксёнов А.В., Ивановская Е.A. Опыт успешного применения тоцилизумаба у ребенка с системным вариантом ювенильного идиопатического артрита. Доктор.Ру. 2021; 20(3): 70-2. [Aksenov A.V., Ivanovskaya E.A. Successful use of tocilizumab in a child with systemic juvenile idiopathic arthritis. Doctor. Ru. 2021; 20(3): 70-2 (in Russian)]. DOI: 10.31550/1727-2378-2021-20-370-72

7. Чомахидзе А.М., Алексеева Е.И., Денисова Р.В. Опыт успешного применения адалимумаба у пациента с ювенильным артритом, ассоциированным с энтезитом и увеитом. Педиатрическая фармакология. 2017; 14(4): 294-9. [Chomakhidze A.M., Alekseeva E.I., Denisova R.V. The experience of successful use of adalimumab in a patient with juvenile arthritis associated with enthesitis and uveitis. Pediatric Pharmacology. 2017; 14(4): 294-9. (in Russian)]. DOI: 10.15690/pf.v14i4.1761

8. Севостьянов В.К., Жолобова Е.С. Увеит, ассоциированный с ювенильным идиопатическим артритом, по данным регистра детей на генно-инженерной биологической терапии в городе Москве. Русский медицинский журнал. 2017; 12: 924-8. [Sevost'yanov V.K., Zholobova E.S. Uveitis associated with juvenile idiopathic arthritis according to the register of children receiving engineered biological therapy in Moscow. Russian Medical Journal. 2017; 12: 924-8. (in Russian)]

9. Burgos-Vargas R., Tse S.M.L., Horneff G. et al. Efficacy and safety of adalimumab in pediatric patient with enthesitis related arthritis. Arthritis Rheumatol. 2014; 66(S3): S4. D0I: 10.1002/ art.38414 D 